\title{
Fenofibrate and losartan
}

\section{T Bardin}

\section{Should we take advantage of their uricosuric properties in clinical practice?}

$\mathrm{T}$ he interesting study published in this issue of the journal by Takahashi et al sheds light on two drugs, losartan and fenofibrate, which have hypouricaemic properties, in addition to their main therapeutic effects.

\section{LOSARTAN}

Losartan potassium is an orally active angiotensin II receptor antagonist used for the treatment of hypertension. This product and its long life metabolite E-3174 are potent antagonists at the ATI receptor. The observation that losartan increases urinary uric acid excretion and reduces serum uric acid level was first made in a pilot study conducted in healthy subjects and published in 1992. Uric acid fractional clearance was mainly increased during the first four hours after drug intake in a time course consistent with a direct effect of the drug. The increase was found to be dose dependent and to persist after seven days of administration. ${ }^{2}$ Angiotensin is known to lower uric acid renal clearance, ${ }^{3}$ but the uricosuric effect of losartan did not appear to be mediated by angiotensin inhibition: in one study, infusion of E-3174, the active metabolite of losartan, did not modify uric acid excretion, although it efficiently decreased blood pressure. ${ }^{4}$ The early and transient uricosuric action of losartan was therefore attributed mainly to the mother compound. Further suggestions of an effect independent of angiotensin II receptor blockade came from the observation that the uricosuric effect did not vary with a sodium diet $t^{5}$ and was not seen with other angiotensin II receptor antagonists. ${ }^{6-8}$

\section{"Losartan and E-3174 target the urate anion exchanger URAT1"}

Losartan and its metabolite E-3174 were recently shown to target the urate anion exchanger URATl and inhibit urate uptake by this transporter, thus reducing urate reabsorption from the proximal tubule, which is the main site of URATl in the human kidney. The effect was of similar order to that of probenecid. $^{9}$

In most clinical studies, losartan was found to increase the fractional excretion of uric acid. The increase was moderate, from 3 to $30 \%,{ }^{10}$ and was not constantly observed. ${ }^{11}$ In some studies, repeated dosing with losartan resulted in a gradual waning of the uricosuric effect, but moderate reduction of serum uric acid was maintained after 3-4 weeks of treatment. ${ }^{112}$ Losartan was also shown to reduce the increase in serum uric acid caused by hydrochlorothiazide, ${ }^{12-14}$ a finding which might be of clinical significance as long term use of diuretics in hypertensive patients is a well known cause of secondary gout. However, this effect was generally not sufficient to totally normalise uricaemia. Losartan also significantly raises urine $\mathrm{pH}$, an interesting property, not shared by other uricosuric drugs, which might counterbalance the risk of uric acid stone associated with increased uric acid excretion. ${ }^{12}$

\section{FENOFIBRATE}

Fenofibrate is a lipid lowering drug, the uricosuric property of which was reported in $1980 .{ }^{15}{ }^{16}$ Fenofibrate has been shown to approximately double uric acid clearance and to significantly reduce the serum uric acid level in healthy volunteers, ${ }^{15}{ }^{17}$ in diabetic and non-diabetic patients with hyperlipidaemia, ${ }^{16} 1819$ and in patients with gout. ${ }^{20}$ Lowering of serum uric acid level was constantly seen across studies and was clinically significant, ranging from 20 to $46 \%$. The uricosuric property is not shared by another fibrate, bezafibrate, despite a similar activity in decreasing serum lipids, so that it does not seem to be related to the lipid lowering effect of fibrates. ${ }^{20}$

\section{COMBINATION WITH CLASSIC URIC ACID LOWERING DRUGS}

The study by Takahashi et al examines the usefulness of the combination of these two uricosuric drugs with the more classic uric acid lowering drugs in the management of gout. ${ }^{1}$ The results, although positive, are a little disappointing, as the observed decreases in serum uric acid were more modest than expected from published data: a mean of 54 $\mu \mathrm{mol} / \mathrm{l}$ ( $15 \%$ reduction) was observed with fenofibrate and of 24 or $30 \mu \mathrm{mol} / \mathrm{l}$ (11-15\% reduction) with losartan. Previous studies of normal subjects by the same group of investigators showed that both losartan potassium and fenofibrate increased not only uric acid clearance but also the urinary excretion of oxypurinol, the main active metabolite of allopurinol. ${ }^{721}$ This leads to the concern that the combination of fenofibrate or losartan with allopurinol might lower the hypouricaemic effect of allopurinol. In the study published in this issue of the journal there was no significant difference in the magnitude of the hypouricaemic effect when fenofibrate or losartan was added to allopurinol or benzbromarone, suggesting that the drug interactions were negligible. ${ }^{1}$

In a short recent report, urate clearance doubled after addition of fenofibrate to allopurinol, ${ }^{20}$ whereas it was only increased by $50 \%$ in the study by Takashashi et al. ${ }^{1}$ An explanation for this milder effect may be that in the latter study the drug was given to patients whose uricaemia had been previously effectively reduced by classic hypouricaemic drugs. Serum uric acid level is an important factor of glomerular filtration and urine excretion of uric acid. A smaller amount of filtered urate might have decreased the ability of fenofibrate to inhibit urate tubular reabsorption.

\section{EFFECT ON BLOOD PRESSURE} AND CARDIOVASCULAR DISEASE

In the absence of gout, the usefulness of the uricosuric action of losartan and fenofibrate in the management of hypertension and dyslipidaemia, respectively, is still difficult to appreciate. Hyperuricaemia is a common finding in both diseases, and the uricosuric property of these drugs may be seen as beneficial as it would contribute to normalisation of the uricaemia in hypertensive and/or hyperlipidaemic subjects. Essential hypertension is associated with increased renal vascular resistance and tubular sodium reabsorption, which are known to decrease urine uric acid excretion $^{22} 23$ and explain the high frequency of associated hyperuricaemia. Hypertension and hypertriglyceridaemia are, together with hyperuricaemia, obesity, glucose intolerance, and type 2 diabetes, frequently part of the insulin resistance syndrome. High serum levels of insulin in this syndrome increase sodium reabsorption and decrease uric acid renal excretion. ${ }^{24}$ Lowering of uricaemia in these patients would be indicated if hyperuricaemia is a risk factor for cardiovascular disease and/or hypertension. Many studies have aimed at determining if hyperuricaemia remains an independent risk factor for cardiovascular disease after controlling for other accepted risk factors. The results have been conflicting. Recent studies, such as the Framingham study, ${ }^{25}$ found that uric acid is not an independent risk factor, whereas others, such as the NHAMES study, ${ }^{26}$ reached 
the opposite conclusion. Faced with this difficulty, most doctors are of the opinion that asymptomatic hyperuricaemia does not deserve any treatment. ${ }^{27}$ However, this view has been recently challenged by the observation that experimental chronic hyperuricaemia in rats was followed by the development of hypertension, which could be prevented or treated by lowering uricaemia with either allopurinol or benziodarone. ${ }^{28}$

\section{"Chronic hyperuricaemia was followed by hypertension prevent- able by lowering uricaemia"}

In this model, the increase in blood pressure was mediated by increased juxtaglomerular renin expression. Hyperuricaemia in rats was subsequently shown to cause glomerulosclerosis and renal arteriopathy, similar to the lesions seen in the kidneys of hypertensive patients. ${ }^{29}$ These animal data are not directly transposable to humans but suggest that studies should be performed to investigate the effect of uric acid lowering drugs on blood pressure and cardiovascular disease in man.

\section{CONCLUSION}

In conclusion, the uricosuric effect of losartan and fenofibrate may be viewed by rheumatologists as an interesting property, which favours the choice of these drugs to treat hypertension and hyperlipidaemia when associated with gout. The uricosuric effect of these drugs should be kept in mind so that steps can be taken to prevent potential uric acid lithiasis, although this side effect does not seem to have been observed thus far. Moreover, it should be emphasised that these drugs are, at present, to be considered as mere adjuvant treatments of hyperuricaemia, as they, especially losartan, have only a mild hypouricaemic effect and have not been registered for the treatment of gout. Whether their use might be interesting in the management of asymptomatic hyperuricaemia associated with dyslipidaemia and/or hypertension remains to be clarified by specific studies.

Ann Rheum Dis 2003;62:497-498

\section{Author's affiliations}

T Bardin, Fédération de Rhumatologie, Hôpital lariboisière, 2 rue Ambroise Paré, 75010 Paris, France

Correspondence to: Professor T Bardin; thomas.bardin@lrb.ap-hop-paris.fr

\section{REFERENCES}

1 Takahashi S, Moriwaki Y, Yamamoto T, Tsutsumi Z, Ka T, Fukuchi M. Effects of combination treatment using anti-hyperuricaemic agents with fenofibrate and/or losartan on uric acid metabolism. Ann Rheum Dis 2003;52:572.

2 Nakashima $M$, Uematsu T, Kosuge $K$, Kanamura M. Pilot study of the uricosuric effect of DuP 753, a new angiotensin II receptor antagonist, in healthy subjects. Eur J Clin Pharmacol 1992;42:333-5.

3 Ferris TF, Gorden P. Effect of angiotensin and norepinephrine upon urate clearance in man. Am J Med 1968;44:359-65.

4 Sweet CS, Bradstreet DC, Berman RS, Jallard N, Saenz A, Weidler DJ. Pharmacodynamic activity of intravenous E-3174, an angiotensin Il antagonist, in patients with essential hypertension. Am J Hypertens 1994;7:1035-40

5 Burnier M, Rutschmann B, Nussberger J, Versaggi J, Shahine S, Waeber B, et al. Salt-dependent renal effects of angiotensin II antagonist in healthy subjects. Hypertension 1993;22:339-47.

6 Minghelli G, Seydoux C, Goy JJ, Burnier M. Uricosuric effect of the angiotensin II receptor antagonist losartan in heart transplant recipients. Transplantation 1998;66:268-71.

7 Puig JG, Mateos F, Buno A, Ortega R, Rodriguez F, Dal-Ré R. Effect of esoprosartan and losartan on uric acid metabolism in patients with essential hypertension. J Hypertens 1999; 17:1033-9.

8 Würzner G, Gerster JC, Chiolero A, Maillard $M$, Fallab-Stubi C-L, Brunner H R, et al. Comparative effects of losartan and irbesartan on serum uric acid in hypertensive patients with hyperuricaemia and gout. J Hypertens 2001;19:1855-60.

9 Enomoto A, Kimura H, Chairoungdua A, Shigeta $\mathrm{Y}$, Jutabha $\mathrm{P}$, Cha $\mathrm{SH}$, et al. Molecular identification of a renal urate-anion exchanger that regulates blood urate levels. Nature 2002;417:447-52

10 Burnier M, Roch-Ramel F, Brunner HR. Renal effects of angiotensin II receptor blockade in normotensive subjects. Kidney Int 1996;49:1787-90

11 Grossman E, Peleg E, Caroll J, Shamiss A, Rosenthal T. Hemodynamic and humoral effect of the angiotensin II receptor antagonist losartan in essential hypertension. Am J Hypertens 1994;7:1041-4

12 Shaninfar $S$, Simpson RL, Carides AD, Thiyagarajan B, Nakagawa Y, Umans JG, ef al. Safety of losartan in hypertensive patients with thiazide induced hyperuricemia. Kidney Int 1999;56:1879-95.

13 Soffer BA, Wright JT, Pratt H, Wiens B, Goldberg Al, Sweet CS. Effects of losartan on a background of hydrochlorothiazide in patients with hypertension. Hypertension 1995;26:112-17.

14 Schoenberger JA for the losartan research group. Losartan with hydrochlorothiazide in the treatment of hypertension. J Hypertens 1995; 13(suppl):S43-7.

15 Desager JP, Hullhoven R, Harvengt $C$. Uricosuric effect of fenofibrate in healthy volunteers. J Clin Pharmacol 1980;20:560-4

16 Harvengt C, Heller F, Desager JP. Hypolipidemic and hypouricemic action of fenofibrate in various types of hyperlipoproteinemia. Artery 1980;7:73-82.

17 Yamamoto T, Moriwaki Y, Takahashi S, Tsutsumi Z, Hada T. Effect of fenofibrate on plasma concentration and urinary excretion of purine bases and oxypurinol. J Rheumatol 2001;28:2294-7.

18 Bastow MD, Durrington PN, Ishola M. Hypertriglyceridemia and hyperuricemia: effects of two fibric acid derivatives (bezafibrate and fenofibrate) in a double blind, placebo-controlled trial. Metabolism 1988;37:217-20

19 Elsaf $M$, Tsichodimos V, Bairaktari E, Siamopoulos KC. Effect of micronized fenofibrate and losartan combination on uric acid metabolism in hypertensive patients with hyperuricemia. J Cardiovasc Pharmacol 1999;34:60-3.

20 Hepburn AL, Kaye SA, Feher MD Fenofibrate: a new treatment for hyperuricemia and gout? Ann Rheum Dis 2001;60:984-6.

21 Yamamoto T, Moriwaki Y, Takahashi S, Tsutsumi Z, Hada T. Effect of losartan potassium, an angiotensin II receptor antagonist, on renal excretion of oxypurinol and purine bases. J Rheumatol 2000;27:2232-6.

22 Cappuccio FP, Strazzulo P, Farinaro E, Trevisan M. Uric acid metabolism and tubular sodium handling. Results from a population-based study. JAMA 1993;270:354-9.

23 Tykarski A. Evaluation of renal handling of uric acid in essential hypertension: hyperuricemia related to decreased urate secretion. Nephron 1991;59:364-8.

24 Reaven GM. The kidney: an unwilling accomplice in syndrome X. Am J Kidney Dis 1997:30:928-31.

25 Culleton BF, Larson MG, Kannel WB, Levy D. Serum uric acid and risk of cardiovascular disease and mortality: the Framingham heart study. Ann Intern Med 1999;131:7-13.

26 Fang J, Alderman MH. Serum uric acid and cardiovascular mortality. The NHAMES I epidemiologic follow-up study 1971-1992. JAMA 2000;283:2404-10.

27 Liang MH, Fries JF. Asymtomatic hyperuricemia: the case for conservative management. Ann Intern Med 1978;88:666-70.

28 Mazzali $\mathbf{M}$, Hughes J, Kim YG, Jefferson JA, Kang DH, Gordon KL, et al. Elevated uric acid increases blood pressure in the rat by a novel crystal-independent mechanism. Hypertension 2001;38:1101-6

29 Mazzali M, Kanellis J, Han L, Feng L, Chen $Q$, Kang $D H$, et al. Hyperuricemia induces a primary renal arteriolopathy in rats by a blood pressure-independent mechanism. Am J Physiol Renal Physiol 2002;282:F991-7. 